"Now, Dirac, put that into your theory! Positive electrons, eh!" Farmelo comments that Kapitsa "had spent hours talking with Dirac but had evidently not even heard of the anti-electron" and that Dirac simply replied "Positive electrons have been in the theory for a very long time". Yet there is no sense that Dirac was claiming anything, apparently convinced that the positive trails in the pictures were "a mirage". Farmelo sees Dirac as exhibiting "reticence taken to the point of perversity". His colleagues so mistrusted his abstract theory that they could not accept that it predicted new particles.

The first link between hole theory and the positron came from Blackett, who showed sensational images of electron-positron pair creation at a meeting at the Royal Society in London, saying that they "fit extraordinarily well with Dirac's hole theory". Immediately afterwards, journalists rushed to interview him. Meanwhile Dirac, who was lecturing in another room in the same building, was "unavailable for comment".

According to Farmelo, Dirac later realized that he held responsibility for not having advocated that experimentalists should hunt for positrons, nor advising on how to detect them. Had he done so, the positron could have been discovered "in a single afternoon", as Anderson put it. When asked later why he did not speak out and predict the positron, Dirac said, "pure cowardice".

Nonetheless, Dirac on other occasions believed that he had predicted it, although not everyone agreed. Blackett said: "Dirac nearly but not quite predicted the positron." So much for history; today, Dirac's role in foreseeing the positron, and the mirror world of antimatter, was, as Farmelo describes it, "one of the greatest achievements in science".

Farmelo concludes The Strangest Man by analysing Dirac's singular character and genius. He makes a sound case that Dirac was autistic, and argues that his behavioural traits were crucial to his success as a theoretical physicist. Cambridge in the 1920s was the ideal environment for him: tolerant of eccentricity; college life providing for his every need; the rules of dining at High Table enabling a rigidly predictable form of social contact. These unusual circumstances enabled Dirac's special genius to flower. As to autism, this is thought to be caused by disrupted brain development, which can show up as irregularities in brain tissue. These can be visualized using positron emission tomography scans - the medical application of Dirac's antimatter. Irony indeed.

Frank Close is professor of physics and a Fellow

at Exeter College, University of Oxford, Oxford,

UK. He is the author of Antimatter.

e-mail: f.close1@physics.ox.ac.uk

\section{The end of the invasion?}

\section{Invasion Biology \\ by Mark A. Davis \\ Oxford University Press: 2009. 288 pp. \$55}

Ascension Island in the South Atlantic Ocean is a good example of the changes that invasive species can wreak. Its volcanic mountain tops once hosted a monotonous carpet of ferns. But in 1843, botanist Joseph Hooker recommended that the bleak island be wooded by importing many new plants - what modern ecologists would see as a massive, human-mediated biological invasion. Surprisingly, this resulted not in ecological meltdown, but in the creation of a lush cloud forest. The forest traps mists, cycles nutrients and survives, generation after generation, without its species having evolved together. A study of this anomalous system is cited in Mark Davis's new book Invasion Biology. Why? Maybe because it is not so anomalous.

Invasion Biology starts out as a graduate-level text on how organisms brought far from their homes by humans can flourish, often at the expense of native species in the places they 'invade'. But on turning the pages, the book reveals itself to be an iconoclastic argument that much of the field's conventional wisdom is wrong, that biologists are more swayed by their emotions about invasive species than they care to admit, and that invasion biology as a field should be disbanded. Davis writes, "This may be the first time that an author has concluded a book, the title of which is the same as the discipline being reviewed, by recommending that participants consider abolishing their discipline."

Davis is not on the fringe. His arguments crystallize a rumbling of dissent recently heard among those who study invasive species. As he puts it, "There is little about biological invasions that make them so unique that a specialized subdiscipline need be sustained to study them."

Invasion biology began in earnest in 1958 when ecologist Charles Elton published his pioneering book, The Ecology of Invasions by Animals and Plants (see Nature 452, 34; 2008). Elton saw species 'invasions' in the context of niches. In an intact, co-evolved ecosystem, every species will have a slightly different role, or niche, and often every niche will be filled. For example, predators eat herbivores; herbivores eat plants; some plants grow on wet soil and some grow on dry. When new species are introduced, the theory goes, they can get a foothold only by finding a vacant niche or by throwing out another species. invasibility hypothesis, which posits that the more species there are in an ecosystem, the more niches will be filled and the harder it will be for a new species to become established.

But the evidence does not bear this out. Many studies have failed to find any strong relationship between how diverse a place is and how easy it is to invade. Davis concludes that, despite its appeal and its "implicit affirmation of the value of diversity", the hypothesis is not true. In fact, the opposite may hold. In any ecosystem, each individual plant or animal has to get a foothold, irrespective of its origin. A seed does not care whether it is exotic or native when it lands on the ground, and neither do the surrounding species. The key insight is that there is nothing fundamentally different about exotics other than where they came from.
Niche theory gives rise to the diversity-

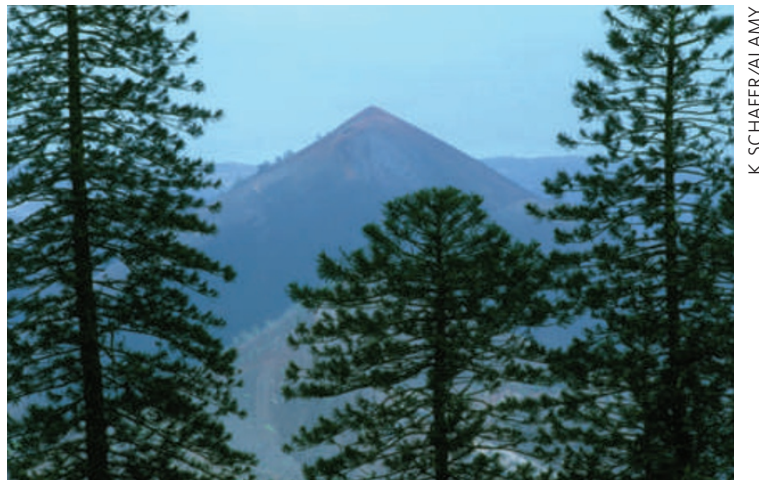

sland: not all imported species are destructive.
Davis challenges other received wisdom, such as the idea that newcomers are more likely to compete with or predate on natives than help them flourish, and that introduced populations are unlikely to be genetically diverse. He refuses to exaggerate the differences between natives and exotics, or to see exotics as the enemy.

Elton's 1958 book was an expansion of a series of radio broadcasts aimed at the public. Davis speculates that this audience was the reason behind Elton's colourful, militaristic comparisons of "ecological explosions" with bombs. This may have sown the seeds of the current 'good-versus-evil' rhetoric of species invasion, with its talk of biological pollution, killer weeds and battling garlic mustard.

Davis is not a fan of such heated rhetoric. He feels that the dichotomous approach is not ecologically enlightening. Life is much messier, more dynamic and more complex, he says. He stuffs the book with examples of exotic species 
that play nicely with their new neighbours. For every pest, there are many more unobtrusive immigrants that live quietly in their new haunts, even helping the growth and development of native species. This does not mean that invading species are never a problem, but Davis argues that they are not always troublesome.

Davis writes well, and clearly. But his big contribution is to the sceptical re-examination of the field as a whole. This book will not kill it off. But if, over time, invasion biology were to become absorbed into broader ecological fields that focus on the movement of species, future historians of science might see Invasion Biology as the beginning of the end.

Emma Marris writes for Nature from Missouri.

\section{Paper ambassadors of science}

\section{Philip Parker of Britain's Royal Mail celebrates special stamps and his new set for the 250th anniversary of the Royal Botanic Gardens at Kew.}

After Queen Elizabeth II, the most featured individual on British postage stamps is a scientist. Charles Darwin has appeared on four stamp issues, in 16 different stamp designs, in the past 30 years. The last set, issued on 12 February this year to commemorate the bicentenary of his birth, used a jigsaw design to illustrate the interconnectedness of the varied disciplines zoology, botany, geology - that Darwin synthesized into his theory of evolution. A separate sheet of four stamps makes up the hydrographic map of the Galapagos Islands that resulted from the voyage of HMS Beagle.

Darwin's popularity as a subject for stamps is appropriate because he was a prodigious letter writer. From its introduction in 1840, the Penny Post was the Internet of its day, facilitating peer review among scientists. With the service came the postage stamp, which is arguably the most widespread and visible platform for public art.

For 50 years, alongside the everyday stamps showing the Queen, Royal Mail has been issuing pictorial stamps to mark aspects of British heritage and contemporary life. They are produced in hundreds of millions, and competition for topics is fierce. Every year Royal Mail receives around 2,000 requests for subjects. These are filtered using certain criteria - anniversaries are covered in 50-year multiples, and themes must be of national importance or celebrate the national character. Intensive desk research and public consultation funnels these down to a continuing programme of around 13 or 14 stamp issues per year.

Subjects are chosen for a range of audiences, from postal historians to the average letter sender. Themes include both light and shade; for example, an impressive set on the grandest cathedrals can be followed by stamps celebrating the fiftieth birthday of the Carry On comedy films - and both can be equally successful.

Postal offices worldwide issue pictorial stamps, and science is frequently celebrated. Scientific concepts are often difficult to illustrate concisely, so scientists are more often depicted. The handsome 2008 stamps from the United States feature portraits of chemist

Published on 19 May, the Royal Mail's latest stamp issue marks the 250th anniversary of the founding of the Royal Botanic Gardens at Kew, near London. A set of four stamps feature images of key landmarks at both Kew and Wakehurst Place in West Sussex, where the Millennium Seed Bank aims to conserve $10 \%$ of the world's seed-bearing flora by 2010 . Alongside are ten stamps of UK endangered plants, many of which Kew is actively conserving. Delicate botanical art is used to portray these species, six examples of which are drawn from Kew's extensive art collection.

Royal Mail works closely with partner organizations, such as Kew, and other experts in the field being portrayed, to cross-check every fact and ensure the content is accurate. In-house specialists commission and manage the work of external designers and illustrators, who may work on the same subject but to different briefs. One specialist might consider photography, another might create new illustrations, and a third could explore existing botanical art. The preferred approach is picked after consultation and discussion with the independent Stamp Advisory Committee. For the ten plant stamps, the style of botanical art was found to give the clearest, most accurate and most engaging depictions in such a small space. Once the final designs are proofed to satisfaction, they are submitted for approval by the Queen before printing.

The Plants sequence is the latest in the Action for Species series. Every year, ten stamps are issued depicting threatened UK species, for which there are conservation plans in place. The series began with Birds in 2007, continued with Insects in 2008, and a set on mammals is being prepared for next year. The series has been devised as a countdown to the International Year of Biodiversity in 2010. Another major set of forthcoming stamps will mark the Royal Society's 350th anniversary in 2010.

Stamps are 'paper ambassadors'. Affixed to letters and parcels, they can end up in any corner of the world, Stamps are arguably the most visible form of public art.

Linus Pauling and astronomer Edwin Hubble, among others.

Indeed, one of the most popular stampcollecting themes globally is astronomy. But flora and fauna are consistently attractive to the public, and science and engineering topics generally do well. Royal Mail's earliest special stamps highlighted the opening of the Forth Road Bridge in 1964, and Jodrell Bank's radio telescope in 1966. However, success is all in the detail and in the translation of the subject on to the tiny canvas of a stamp. where the receiver will form an opinion of the sender, of the country of origin, that country's sense of self and its global contribution. This is why Royal Mail pays so much attention to detail on its stamps - they illustrate, in the best sense, the best of British.

Philip Parker is head of stamp policy at Royal Mail, 35 Rathbone Place, London W1T 1HQ, UK. e-mail:philip.parker@royalmail.com

For details of Royal Mail's Plants stamps, see online at www.royalmail.com/plants. 